\title{
THERMOMECHANICAL AND RHEOLOGICAL BEHAVIOURS OF WASTE GLASS FIBRE-FILLED POLYPROPYLENE COMPOSITES
}

\author{
Sunan Tiptipakorn ${ }^{1}$, Sarawut Rimdusit ${ }^{2}$ \\ Siriporn Damrongsakkul ${ }^{2 *}$ and Takeshi Kitano ${ }^{3}$
}

${ }^{1}$ Department of Chemistry, Faculty of Liberal Arts and Science,

Kasetsart University, Kamphaensaen, Nakhorn Pathom, Thailand 73140

2 Department of Chemical Engineering, Faculty of Engineering,

Chulalongkorn University, Bangkok, Thailand 10330

${ }^{3}$ Polymer Centre, Faculty of Technology,

Tomas Bata University in Zlin, Czech Republic 76001

E-mail : faassntk@ku.ac.th ${ }^{1}$, sarawut.r@eng.chula.ac.th²

siriporn.d@chula.ac.th ${ }^{2 *}$ and kitano@ft.utb.cz ${ }^{3}$

\section{ABSTRACT}

The composites between the reinforced glass fibre wastes obtained from surfboard manufacturing industry and polypropylene were developed for value adding and environmental reasons. The thermomechanical and rheological behaviours of the composites were investigated. Glass fibre contents were varied from 5 to $30 \mathrm{wt} \%$. The effects of maleic anhydride grafted polypropylene (MA-PP) compatibilizer on the behaviours were also determined. The results revealed that the addition of glass fibre was able to reduce the heat of fusion of the composite. Additionally, the tensile and flexural properties were increased with increasing the glass fibre contents following the rule of mixtures. The addition of MA-PP led to enhance tensile and flexural properties due to the improvement of the adhesion between matrix and glass fibre, which is correlated with morphological observations. From the rheological studies, the apparent flow activation energy revealed that the addition of glass fibre decreased the fluidity of the molten composite materials; however, it could be slightly improved by using MA-PP.

\section{KEYWORDS}

polypropylene, glass fibre, waste, surfboard manufacturing, composite 


\section{Introduction}

In the surfboard manufacturing, a large amount of wastes (containing glass fibre reinforced with epoxy) has been continuously generated due to mass consumption. The increasing awareness about the environment has greatly contributed to the concerns related with disposal of the generated wastes. The two most common methods to dispose the waste are land filling and incineration. The former method has some shortcomings due to the rising costs of construction and operation, while the later method has the problems from the ash pollution [1]. Due to the outstanding properties of glass fibre, the waste was proposed to utilize with the commodity plastic such as polypropylene. The advantage of the use of this waste material is not only the decrease of the environmental problems but also the addition of waste value and the reduction of budget to eliminate the waste. There have been numerous studies on applying glass fibre to many polymers such as polyamide [2], [3], polystyrene [4], poly(ethylene terepthalate) [5], [6] , and polyolefins [7] - [9]. Some researches were focused on maleated natural rubber/polypropylene composites [10] or pristine glass fibre and polypropylene [11]. However, a few studies on the commodity polymers reinforced with waste glass fibre were reported.

This present article intends to preliminarily investigate the recycleability of the glass fibre waste from surfboard production as a filler to reinforce polypropylene. Additionally, the thermomechanical and rheological behaviours of the composites were investigated. The effects of maleic anhydride grafted polypropylene (MA-PP) on the behaviours were also determined.

\section{Materials and Methods}

\section{Materials}

A commercial grade of polypropylene (EL-Pro $\left.{ }^{\mathrm{TM}} \mathrm{P} 700 \mathrm{~J}\right)$ with a density of $0.910 \mathrm{~g} / \mathrm{cm}^{3}$ and a melt flow index of $12 \mathrm{~g} / 10 \mathrm{~min}$ was provided by Thai Polypropylene Co., Ltd. The scrap of glass fibre wastes reinforced with cured epoxy (epoxy resin (SR1270) and base hardener (SD4999) was obtained from the surfboard manufacturing industry (Cobra International Co., Ltd.). Maleic anhydride grafted polypropylene (MA-PP) under the trademark of Dupont ${ }^{\mathrm{TM}}$ Fusabond ${ }^{\circledR}$ P MZ109D was supplied by Creative Polymers Co., Ltd.

\section{Preparation of composite samples}

The reinforced glass fibre wastes (laminated sheets, ca. $1 \mathrm{~mm}$ thick) were cut in small pieces (ca. $10 \mathrm{~mm} \times 10 \mathrm{~mm}$ ) using a PSG500 model plastic crusher (Longxiang Plastic Machinery Factory, China) and then ground in a rotating blade grinder (Moulinette, Moulinex, Alecon, France) for 60 seconds and size-classified. These fibres were dried at $90^{\circ} \mathrm{C}$ for 2 hours before mixing with PP and MA-PP in a dry blend mixer at $1000 \mathrm{rpm}$ for 5 minutes. The ground fibres were mainly composed of single fibres and a small amount of fibre cluster as presented in Table 1. The mixtures were further mixed in a twin screw extruder (Hakke, Polylab-Rheomex, CTW100P, Germany) at the cylinder temperature of $180^{\circ} \mathrm{C}$. In this study, codes of composite samples and mixing weight ratios are summarized in Table 2. Extrudates were cut into pellets and dried before the preparation of $1 \mathrm{~mm}$ thick plates by compression moulding at $180^{\circ} \mathrm{C}$ and $9.8 \mathrm{MPa}$. The round specimens with $25 \mathrm{~mm}$ diameter for rheological measurements were cut from the plates.

\section{Rheological study}

Viscoelastic properties of the samples such as storage modulus (G'), loss modulus (G") and complex viscosity $(n)$ were determined under oscillatory flow by a rotational rheometer (ARES, Rheometrics, USA) with a parallel plate geometry (plate diameter $25 \mathrm{~mm}$, gap between plates ca. $1 \mathrm{~mm}$ ) equipped with RSI orchestrator software package. Measurements were carried out at the temperatures of 180,200 and $220^{\circ} \mathrm{C}$ and strain amplitude $\left(\mathrm{\gamma}_{0}\right)$ of $1 \%$ and angular frequencies $(\omega)$ in the range from 0.1 to $100 \mathrm{rad} / \mathrm{sec}$. Strain (amplitude) dependence of the samples was also investigated by changing $\gamma_{0}(10,25$ and $50 \%)$ and also by strain sweep test at the temperature of $180^{\circ} \mathrm{C}$. 
Table 1

Diameters and lengths of ground fibres

\begin{tabular}{|c|c|c|c|}
\hline Characteristic & Diameter (microns) & Length (mm) & Amount (\%) \\
\hline \multirow{4}{*}{ Single Fibre } & \multirow{4}{*}{12} & $100-500$ & 32 \\
\hline & & $500-1000$ & 23 \\
\hline & & $1000-2000$ & 21 \\
\hline & & $>2000$ & 7 \\
\hline \multirow{3}{*}{ Fibre Cluste } & \multirow{3}{*}{ - } & $100-500$ & 9 \\
\hline & & $500-1000$ & 6 \\
\hline & & $1000-2000$ & 2 \\
\hline
\end{tabular}

Table 2

Diameters and weight ratios of PP, PP-g-MA and glass fiber in each sample

\begin{tabular}{|c|c|c|c|}
\hline Sample Code & PP & PP-g-MA & Glass Fiber \\
\hline PP & 100 & - & - \\
\hline 5GF2MA & 93 & 2 & 5 \\
5GF5MA & 90 & 5 & 5 \\
\hline 10GF2MA & 88 & 2 & 10 \\
10GF5MA & 85 & 5 & 10 \\
\hline 15GF2MA & 83 & 2 & 15 \\
15GF5MA & 80 & 5 & 15 \\
\hline 20GF2MA & 78 & 2 & 20 \\
20GF5MA & 75 & 5 & 20 \\
\hline 25GF2MA & 73 & 2 & 25 \\
25GF5MA & 70 & 5 & 25 \\
\hline 30GF2MA & 68 & 2 & 30 \\
30GF5MA & 65 & 5 & 30 \\
\hline
\end{tabular}

\section{Thermal analysis}

Differential Scanning Calorimeter (DSC) of TA instruments (model DSC2910), calibrated with Indium standard, was used. A sample of about $10 \mathrm{mg}$ was used for each test. In order to erase any thermal history, the samples were heated at $10^{\circ} \mathrm{C} / \mathrm{min}$ from 30 to $200^{\circ} \mathrm{C}$. Then, they were cooled to the ambient temperature, and scanned again using the same heating rate as before. The glass transition temperatures $\left(T_{g}\right)$ of the blends were measured.

The decomposition temperature $\left(T_{d}\right)$ and char yield of the blends were studied using TGA Instruments (model TGA/SDTA $851^{\mathrm{e}}$ ). The experiments were performed using a heating rate of $20^{\circ} \mathrm{C} / \mathrm{min}$ from 30 to $800^{\circ} \mathrm{C}$ under nitrogen atmosphere. 


\section{Mechanical property measurement}

Tensile modulus, tensile strength and elongation at break of the composite samples were determined using a universal testing machine (model 5567) from Instron Co., Ltd. The test method used was a tension mode with a specimen dimension of $165 \mathrm{~mm} \times 13 \mathrm{~mm} \times 3 \mathrm{~mm}$, dumbbell shape. The specimen gauge length was $10 \mathrm{~cm}$ and the crosshead speed for testing was $50 \mathrm{~cm} / \mathrm{min}$. The tensile properties were obtained following the general procedure in ASTM D638 using seven specimens per test condition.

The flexural properties of the composite specimens were determined using the same universal testing machine. Following ASTM D 790M-93, the test was carried out in three point bending mode with a support span of $32 \mathrm{~mm}$ using a constant crosshead speed of 0.85 $\mathrm{mm} / \mathrm{min}$. The sample dimension was $25 \mathrm{~mm} \times 50 \mathrm{~mm} \times 2 \mathrm{~mm}$. Seven samples were used to determine the average property values.

\section{Scanning electron microscopy observation}

The morphology of fracture surfaces of the composites was observed by a scanning electron microscope (SEM), JEOL JSM 6300, with field emission gun and accelerating voltage of 10 $\mathrm{kV}$. Prior to the SEM observation, a few nanometers gold film was coated on the fracture surfaces.

\section{Results and Discussions}

Figure 1 shows the DSC thermograms of PP-glass fibre composites at various glass fibre contents. It can be observed that there was no significant effect of the glass fibre contents on the melting temperatures (around $165^{\circ} \mathrm{C}$ ). However, the added glass fibre was able to reduce the amount of heat consumed for melting the composite, i.e. the heat of melting for the composite with $30 \mathrm{wt} \%$ of glass fibre was around $30 \%$ lower than that for pure polypropylene. It could be because of the decrease in the amount of PP. The advantage of this phenomenon is that the small amount of energy consumption is required to process the composite when glass fibre is incorporated.

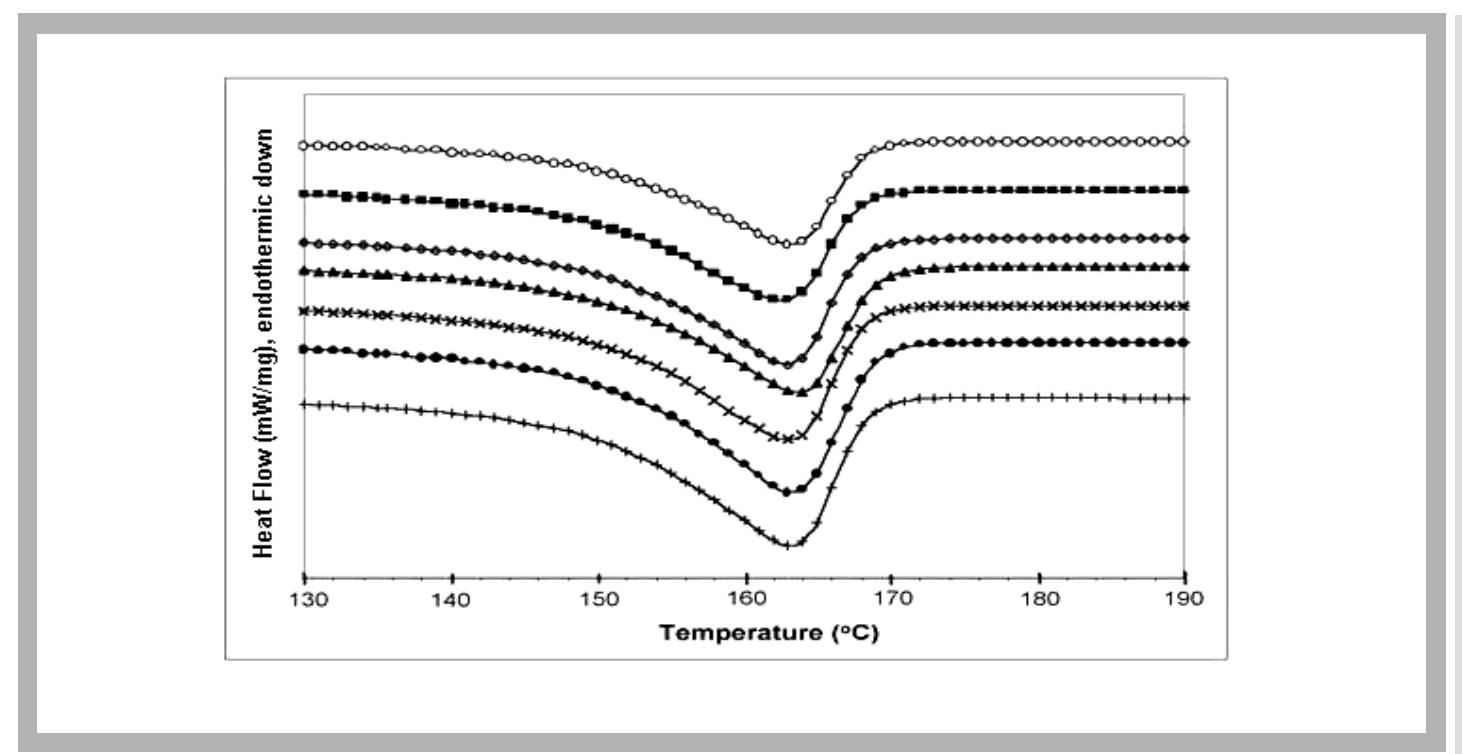

Table 3 presents the decomposition temperatures at $5 \%$ weight loss and char yield of the composites with MA-PP at various glass fibre contents in comparison with those of pure polypropylene. It could be noticed that the addition of glass fibre was able to enhance the decomposition temperatures of the polymer. Additionally, the char yields of the composites were reported to be lower than the amounts of added filler by approximately $30 \%$. The values were possibly related to the weight of added glass fibre without adhesives.
Figure 1:

DSC thermograms of the composites at various $\mathrm{GF}$ contents, (2wt\% MA-PP):

(+) Pure PP,

(•) $5 \mathrm{wt} \%$,

(x) $10 \mathrm{wt} \%$,

(A) $15 \mathrm{wt} \%$

(৩) $20 \mathrm{wt} \%$,

(•) $25 \mathrm{wt} \%$,

(०) $30 w t \%$ 
Table 3

Degradation

temperatures and

char yiled at $800^{\circ} \mathrm{C}$

from TGA

characterization

under nitrogen

atmosphere

\begin{tabular}{|c|c|c|}
\hline Sample & $\begin{array}{c}\text { Decomposition } \\
\text { Temperature } \\
\text { at 5\% Weight Loss }\left({ }^{\circ} \mathbf{C}\right)\end{array}$ & $\begin{array}{c}\text { Char Yield at } 800^{\circ} \mathbf{C}, \\
\text { (\%) }\end{array}$ \\
\hline Pure PP & 364 & 0 \\
\hline 10FG5MA & 372.3 & 7 \\
\hline 20FG5MA & 374.3 & 13.9 \\
\hline 30FG5MA & 381.7 & 20 \\
\hline
\end{tabular}

Figure 2

Tensile strength

of PP-glass fibre

composites at

different MA-PP

loadings:

2MA-PP

5MA-PP

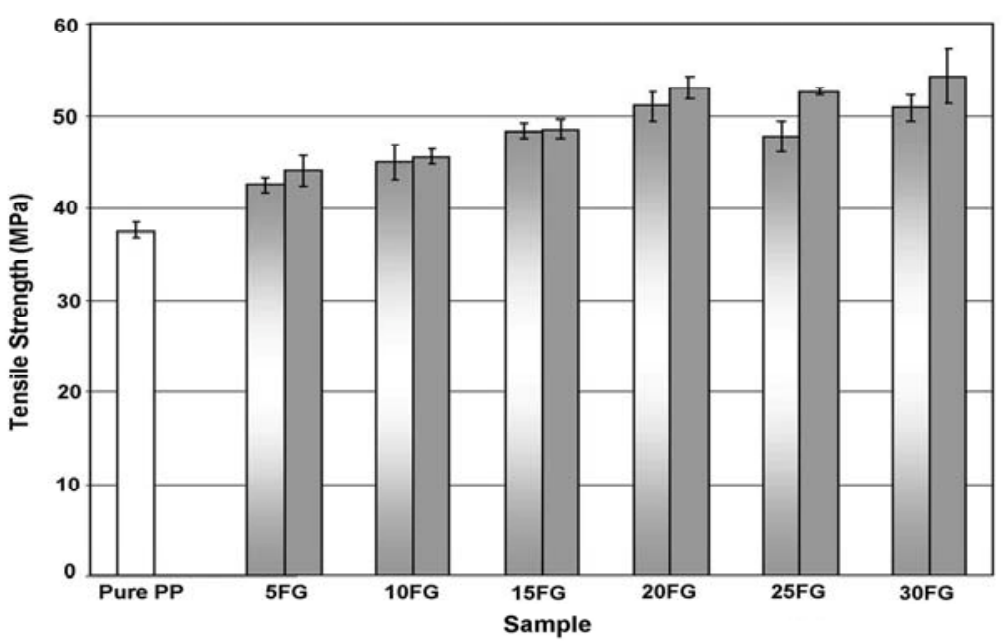

The effect of glass fibre contents on the tensile strength of the composite is exhibited in Figure 2. At the same content of maleic anhydride grafted polypropylene (MA-PP), it shows that the tensile strength tended to increase with increasing glass fibre content since the strength of glass fibre (reinforcing element) is greater than that of pure polypropylene matrix. From the experiment, the tensile strength of 30FG5MA was around $45 \%$ higher than that of pure polypropylene. In comparison between the composites at different MA-PP contents, the tensile strengths of composites at $5 \mathrm{wt} \%$ MA-PP were slightly higher $(4 \%)$ than the ones at $2 w t \%$ MA-PP. This tensile strength enhancement was also found in the similar system of short glass fibre reinforced PA6 and ABS blends [12]. The tensile strength of short fibre composite is commonly expressed as followed.

$$
\sigma_{c}=K_{\delta} \sigma_{f} v_{f}+\sigma_{m} V_{m}
$$

where $\sigma_{c}$ is tensile strength of the composite; $K_{\delta}$ is overall efficiency factor for reinforcement; $\sigma_{f}$ is tensile strength of the fibre; $V_{f}$ is volume fraction of the fibre; $\sigma_{m}$ is tensile strength of the matrix; $V_{m}$ is volume fraction of the matrix. 
In general, the interface between fibre and matrix is related to the load transmission from the matrix to the fibre, which contributes to the composite strength. In case of good interfacial adhesion, the value of $K_{\sigma}$ was high. When MA-PP was added to enhance the adhesion between the fibre and polypropylene, the loading force was effectively transferred from the low-strength matrix to high-strength fibre [12], [13].

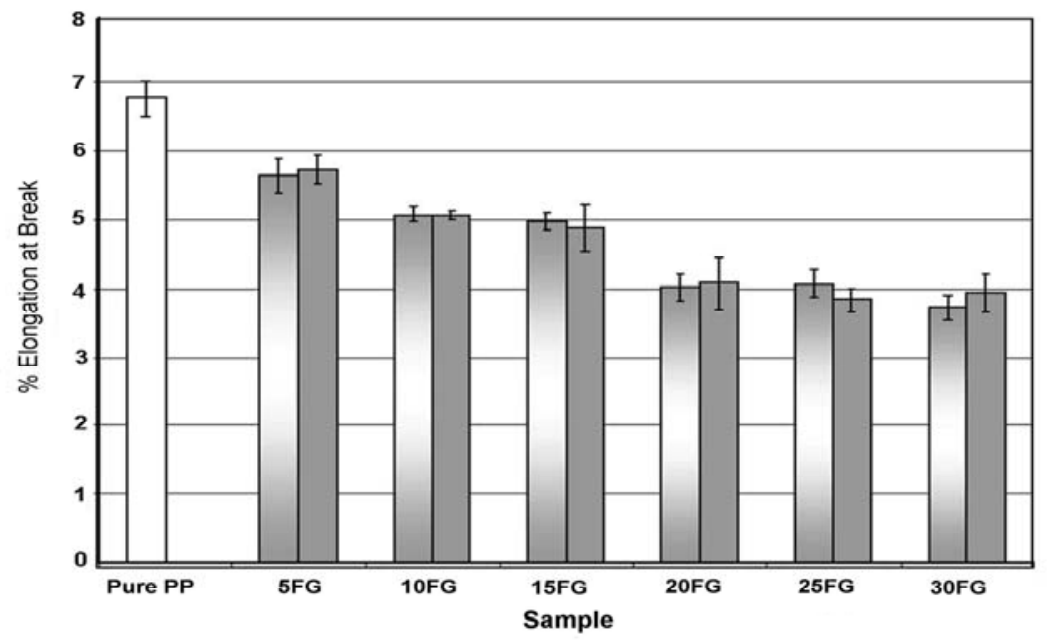

Figure 3

$\%$ elongation at break of PP-glass fibre composites at different MA-PP loadings:

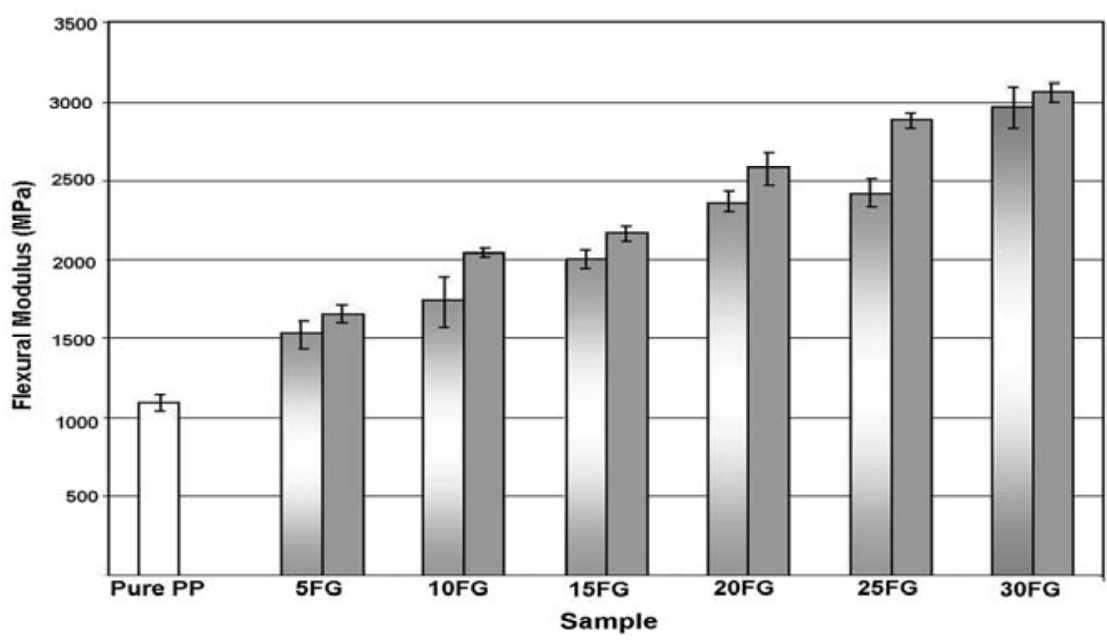

Figure 4

Flexural modulus of PP-glass fibre composites at different MA-PP loadings:

\section{MA-PP} 5MA-PP

Figure 3 presents the percentage elongation of PP-glass fibre composites at various glass fibre contents with $2 \mathrm{wt} \%$ and $5 \mathrm{wt} \%$ of MA-PP loadings. The results reveal that the addition of glass fibre decreases the elongation at break of the composite because the glass fibre and epoxy resin waste from surfboard production are rather stiff and brittle. Therefore, the composites have lower elasticity than pure polypropylene. Furthermore, the breakage of the material initiates from the interface between polymer matrix and additives. When the glass fibre increased, the breakage increased. The experimental results show that the percentage of elongation of 30FG5MA was $70 \%$ decreased from that of pure polypropylene. The addition of MA-PP leads to a slight increase in the elongation at break, i.e. the elongation at $5 \%$ of MA-PP was about $3-6 \%$ higher than that at $2 \%$ of MA-PP, due to high adhesion between glass fibre and polypropylene.

Figure 4 illustrates the flexural modulus of the composites at various glass fibre contents. It can be observed that the flexural modulus of the composites was enhanced with increasing the glass fibre content. This due to the much higher modulus of glass fibre, approximately 78 $\mathrm{GPa}$ at $50 \mathrm{~mm}$ test length, comparing to that of pure polypropylene, approximately $1.3 \mathrm{GPa}$ [13]. Following the rule of mixtures [14], the composite between polypropylene and glass fibre was able to resist higher flexural modulus than that of the matrix, i.e. the modulus of 30FG5MA was approximately $180 \%$ increased from that of pure polypropylene. In 
consideration of the effect of MA-PP content on the flexural modulus, it was found that the flexural modulus of the composite with $5 \mathrm{wt} \%$ of MA-PP was higher than that of $2 \mathrm{wt} \%$ of MA$\mathrm{PP}$ at the same glass fibre content, because of the higher adhesion between the fibre and the matrix [12]. Generally, the flexural modulus and elastic modulus of the composite material exhibit the same values. The modulus of the hybrid composite can be evaluated from the rule of hybrid mixture equation by neglecting the interaction between two systems as follows [15]:

$$
E_{c}=E_{c 1} V_{c 1}+E_{c 2} V_{c 2}
$$

where $E_{c}, V_{c 1}$ and $V_{c 2}$ are the elastic modulus of the hybrid composite, the relative hybrid volume fraction of the first and the second system, respectively.

The flexural strength of the matrix and the composites presented in Figure 5 revealed that the addition of glass fibre tended to increase with the increase of flexural strength at the same MA-PP contents, i.e. the flexural strength of 30FG5MA was approximately $40 \%$ increased from that of pure polypropylene. The trend observed in flexural strength is similar to that found in tensile strength. Additionally, the flexural strength was increased with increasing the MA-PP contents because of better adhesion between fibre and matrix as previously discussed.

Figure 5

Flexural strength of PP-glass fibre composites at different MA-PP loadings:

2MA-PP

5MA-PP
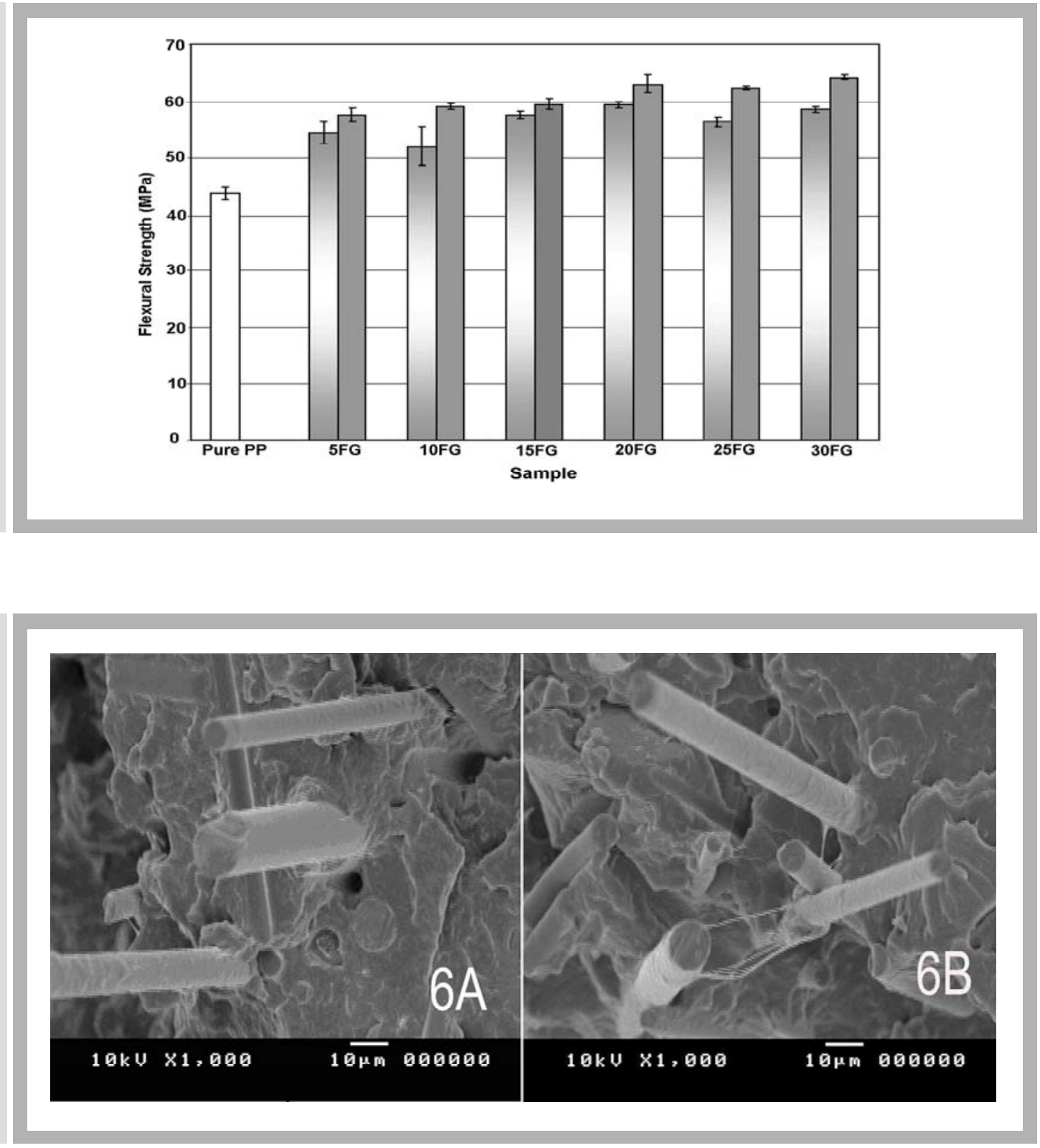

Figure $6 \mathrm{~A}$

Fracture surface of 30FG2MA sample (x 1000 magnifications)

Figure $6 \mathrm{~B}$ Fracture surface of 30FG5MA sample (x 1000 magnifications) 
Figures $6 \mathrm{~A}$ and $6 \mathrm{~B}$ exhibit the SEM micrographs of the fracture surface from tensile test of the composite containing $30 w t \%$ of glass fibre at $2 \mathrm{wt} \%$ and $5 \mathrm{wt} \%$ of MA-PP compatibilizer, respectively. It can be clearly seen that the fracture surface was rough and most of the fibres were in random orientation. The fracture surface was featured by some holes due to the pulled out fibres and the protruding fibres on the fracture surface. The number of holes from the pulled- out fibre of the composite with $5 \mathrm{wt} \%$ of MA-PP was less than that of the composite with $2 \mathrm{wt} \%$ of MA-PP. Furthermore, the surface wetting of the polymer matrix on the glass fibre at $5 w t \%$ of MA-PP was greater than that of the fibre at $2 w t \%$ MA-PP. It indicates an enhancement of interfacial interaction between two phases.

Figures 7A, 7B, and 7C exhibit the effect of MA-PP on the dynamic viscoelastic properties (storage modulus, loss modulus, and complex viscosity, respectively) as a function of angular frequency of the composite at $20 \mathrm{wt} \%$ glass fibre at the temperature of $180^{\circ} \mathrm{C}$ in molten state. In Figures 7A and 7B, it could be observed that the storage modulus and loss modulus of the composite was increased with increasing angular frequency. Furthermore, the composites with 5wt\% MA-PP had the highest storage and loss modulus, while the composites without MA-PP had the lowest storage and loss modulus. In Figure 7C, the complex viscosity of the composite was decreased with increasing angular frequency. The composites with $5 \mathrm{wt} \%$ MA-PP had the highest complex viscosity, while the composites without MA-PP had the lowest complex viscosity. This indicates the enhancement of fibrematrix interfacial adhesion in presence of MA-PP. This phenomenon is similar to the viscoelastic behaviours found in the rheological study of MA-PP treated PP/sisal composites [16].
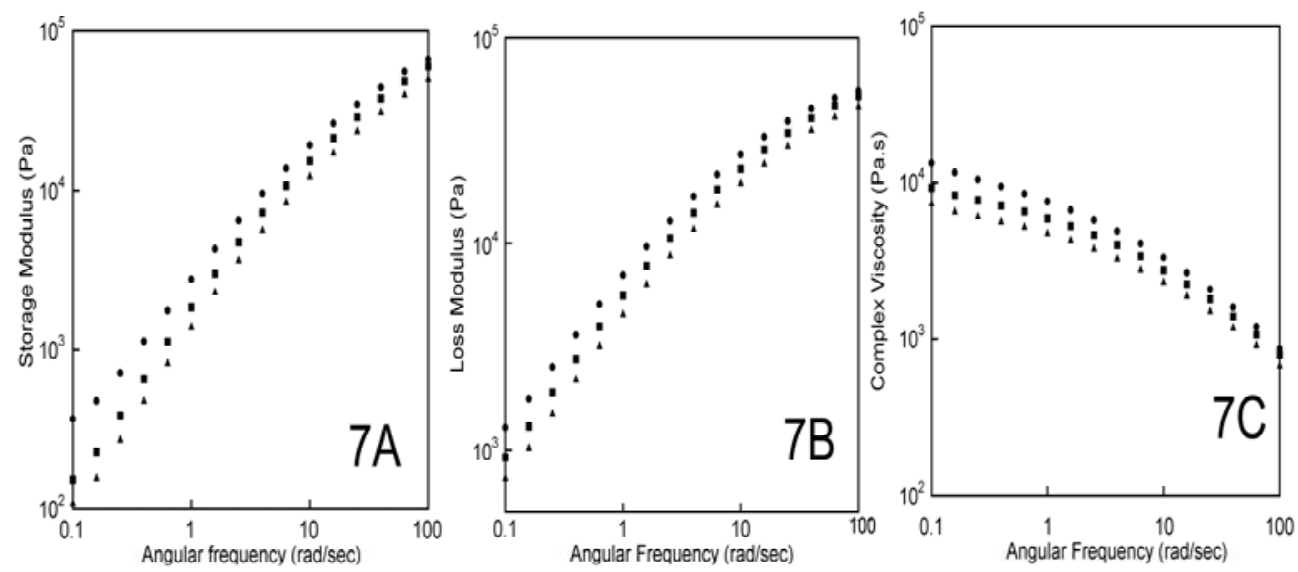

Figure 7

Effect of MA-PP of

GF-PP composite at $10 \%$ strain for $20 \%$ GF content:

(ム) GF-PP without MA-PP,

(•) 20GF2MA,

(•)20GF5MA
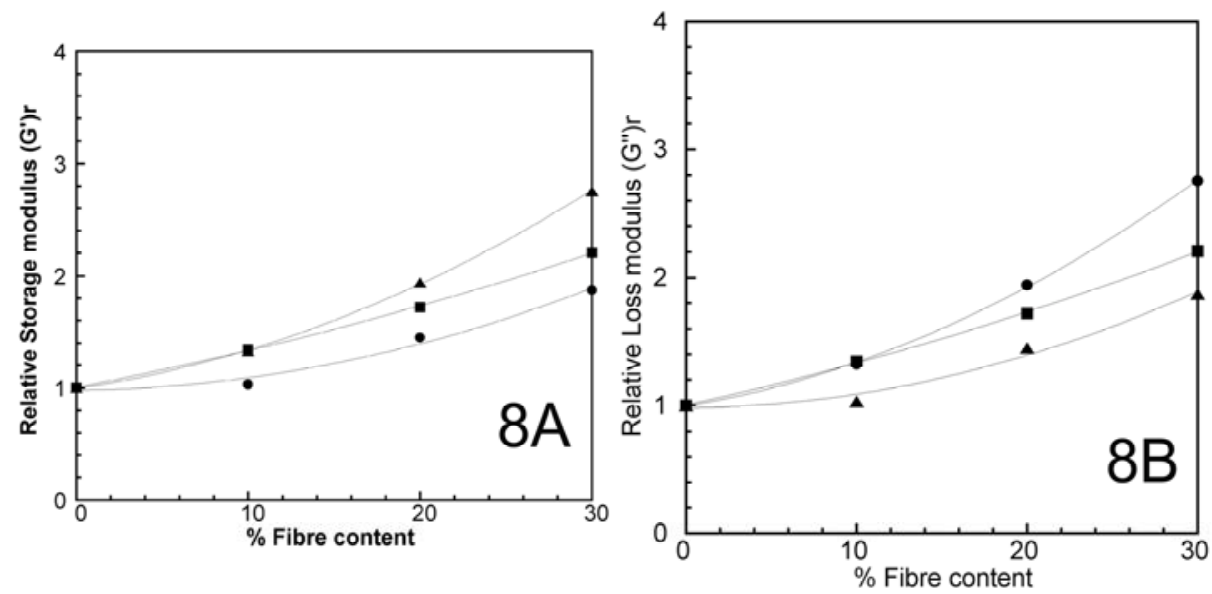

Figure 8 Effect of fibre content at $50 \%$ strain on relative storage modulus (Figure 8A) and relative loss modulus (Figure 8B) 
In order to clarify the influence of fibre content on the viscoelastic properties of the composites with and without MA-PP in molten state, the relations between the relative storage modulus $\left(\mathrm{G}^{\prime}\right) \mathrm{r}$ and fibre content at $50 \%$ strain and those between loss modulus $\left(\mathrm{G}^{\prime \prime}\right) \mathrm{r}$ and fibre content at the angular frequency of $3.9 \mathrm{rad} / \mathrm{sec}$ are shown in Figures $8 \mathrm{~A}$ and $8 \mathrm{~B}$, respectively. It was obviously shown that at low fibre content both storage modulus and loss modulus of the composite gradually increased with glass fibre content, and then significantly increased with increasing the glass fibre content. That could be attributed to the fact that the fibre rigidity or flexibility was slightly reflected in G' and G" at low fibre content. This phenomenon is also found in other composite systems, such as polyamide fibre reinforced polypropylene, and polyvinyl alcohol fibre reinforced polypropylene [17], [18]. Additionally, both storage modulus and loss modulus of the composite with 5wt\% of MA-PP were higher than those of the composite with $2 \mathrm{wt} \%$ of MA-PP and that of the composite without MA-PP. This could be due to the effect of MA-PP on the enhancement of the fibre-matrix interfacial adhesion and hence the load transfer as previously mentioned.

The relationships between the storage modulus and angular frequency and those between the loss modulus and angular frequency of pure PP and PP-GF at various temperatures are presented in Figures $9 \mathrm{~A}$ and $9 \mathrm{~B}$, respectively. It could be observed that both storage and loss moduli were increased with increasing the angular frequency, which is attributed to the shortened time available for molecular relaxation. Furthermore, the moduli of the composites were found to be higher than those of unfilled polypropylene. It is obviously noticed that, at any given test frequency for the same observed temperature the addition of MA-PP led to the increase of both storage and loss moduli. This is possibly because of the adhesion improvement between fibre and polymer matrix in the presence of MA-PP. In addition, it was found that the increase of measuring temperature had an effect on the decrease of both storage and loss modulus.

Figure 9

Effect of temperature on storage and loss modulus

(०) $180 \mathrm{C}$ (pure PP)

(口) 200C (pure PP)

$(\diamond) 220 \mathrm{C}$ (pure PP),

(•) $180 \mathrm{C}(20 \mathrm{GF}$ no

MA-PP), (ロ) 200 C

(20GF_no MA-PP),

(४) $220 \overline{\mathrm{C}}(20 \mathrm{GF}$ no

MA-PP),

(+) $180 \mathrm{C}$

(20GF2MA), $(\triangle)$

200C (20GF2MA),

$(\nabla) 220 C$

(20GF2MA), (ई) $180 \mathrm{C}$

20GF5MA

(ム) $200 \mathrm{C}$

(20GF5MA)

( $\mathbf{\nabla}) 220 \mathrm{C}(20 \mathrm{GF} 5 \mathrm{MA})$
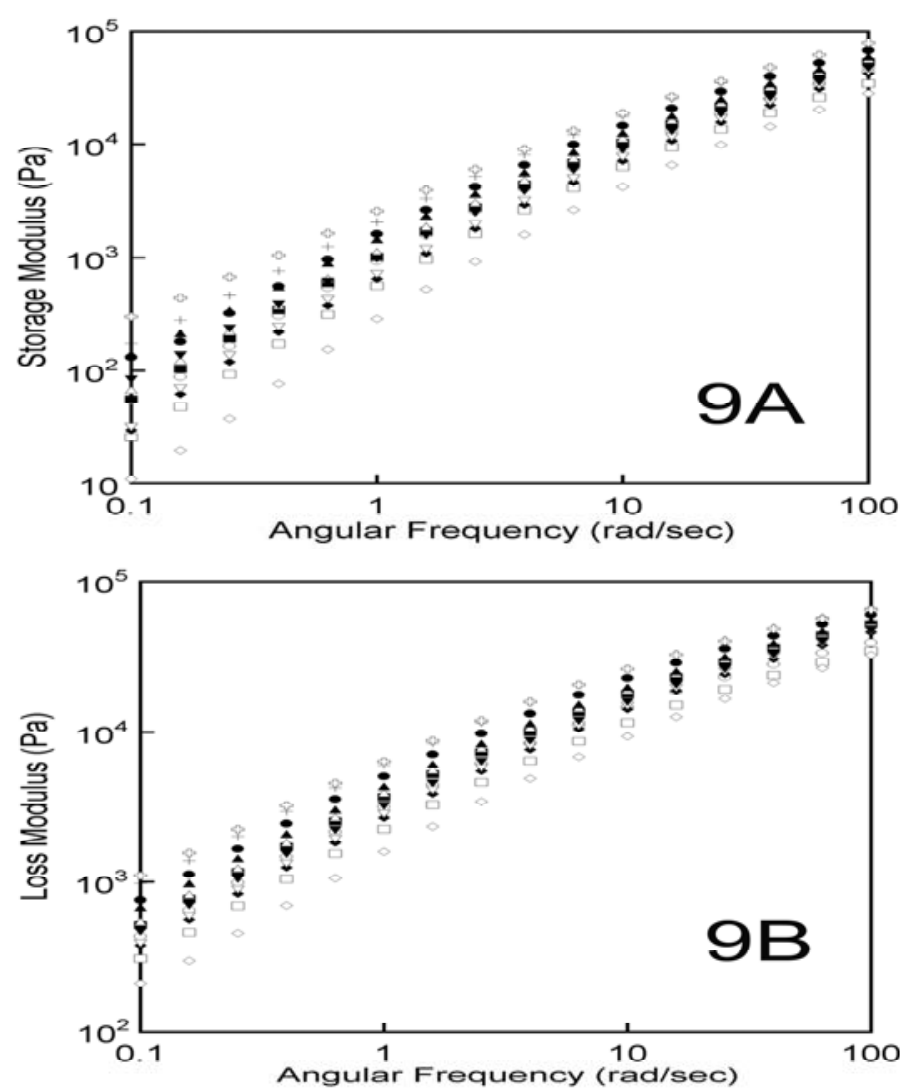
The storage modulus, G' of pure PP and PP-GF is plotted against the reciprocal of the absolute temperature, $1 / T$ in Figure 10. The results depicted in the figure were obtained at an angular frequency of $3.9811 \mathrm{rad} / \mathrm{s}$ and measured at 180,200 , and $220^{\circ} \mathrm{C}$. From the slopes of $G^{\prime}$ versus $1 / T$ plots, the apparent activation energy, Ea, can be calculated as shown in Table 4. These values are quantitatively measured to evaluate the fluidity of the materials, i.e. the fluidity of the material is enhanced with increasing activation energy [17], [19]. The Ea is not constant for filled systems; however, it depends on the volume fraction of solid [20]. From Table 4, it can be observed that the addition of glass fibre led to an increase in the viscosity and also a decrease in the fluidity of the molten composites. Furthermore, the composites with MA-PP had slightly greater fluidity than the composites without MA-PP.

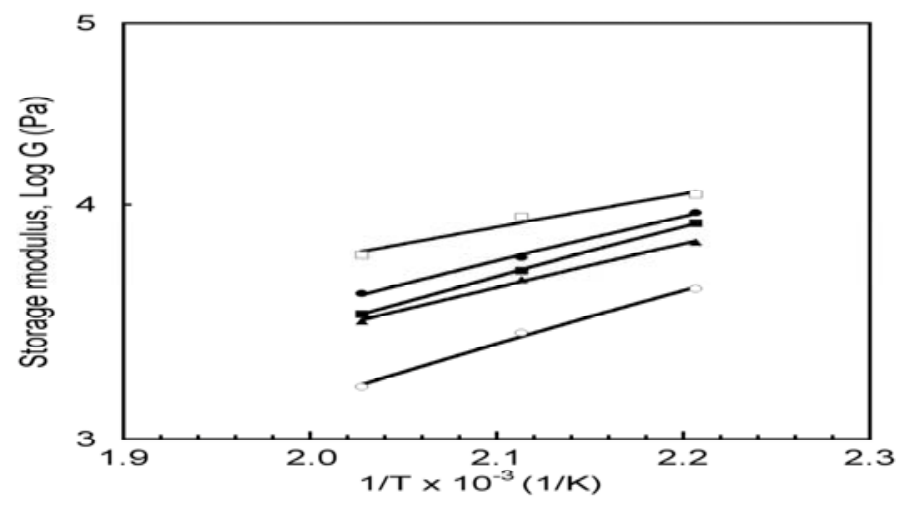

\begin{tabular}{|c|c|}
\hline Material & Ea ( kcal/mol) \\
\hline pure PP & 10.2 \\
\hline PP with 20GF (no MA-PP) & 8.6 \\
\hline PP with 30GF (no MA-PP) & 6.3 \\
\hline 20GF2MA & 10 \\
\hline 20GF5MA & 8.9 \\
\hline
\end{tabular}

\section{Conclusions}

The addition of glass fibre waste obtained from surfboard manufacturing industry was able to reduce the heat of fusion of polypropylene composite because of the decrease in the amount of PP. The TGA results reveal the enhancement of $\mathrm{Td}$ in the presence of glass fibre. Furthermore, the tensile and flexural properties of the composites were increased with increasing the glass fibre contents. The addition of MA-PP led to the enhancement of the fibre-matrix interfacial adhesion and hence the load transfer. The morphological observations by scanning electron microscopy show the slight interfacial improvement after the addition of MA-PP. The results from rheological studies were able to provide the apparent flow
Figure 10

Influence of temperature on storage modulus:

(o) pure PP,

(ム )20GF (no MA-PP),

(口) $30 \mathrm{GF}$ (no MA-PP)

(-) 20GF2MA,

(•) 20GF5MA
Table 4

Apparent activation energy (Ea of the glass fibre reinforced composites (at $3.9811 \mathrm{rad} / \mathrm{s}, 1 \%$ strain) 
activation energy, which could reveal that the addition of glass fibre decreased the fluidity of the molten composite materials; however, the fluidity could be slightly improved by using MA-PP. 


\section{REFERENCES}

T. Narayana, "Municipal solid waste management in India: From waste disposal to recovery of resources," Waste Management, vol. 29, no. 3, pp. 1163-1166, 2009.

[2] A. Bernasconi, P. Davoli, D. Rossin, and C. Armanni, "Effect of reprocessing on the fatigue strength of a fiber glass reinforced polyamide," Composites Part A : Applied Science and Manufacturing, vol. 38, no. 3, pp. 710-718, 2007.

[3] A. Bernasconi, D. Rossin, and C. Armanni, "Analysis of the effect of mechanical recycling upon tensile strength of a short glass fibre reinforced polyamide 6,6," Engineering Fracture Mechanics, vol. 74, no. 4, pp. 627-641, 2007.

[4] C. Shin, "Filtration application from recycled expanded polystyrene," Journal of Colloid Interface Science, vol. 302, no. 1, pp. 267271, 2006.

[5] A. Pegoretti and A. Penati, "Recycled poly(ethylene terephthalate) and its short glass fibres composites: Effects of hygrothermal aging on the thermo-mechanical behaviour," Polymer, vol. 45, no. 23, pp. 7995- 8004, 2004.

[6] A. L. F. Giraldi, J. R. Bartoli, J.I.Velasco, and L. H. I. Mei, "Glass fibre recycled poly(ethylene terephthalate) composites: Mechanical and thermal properties, " Polymer Testing, vol. 24, no. 4, pp. 507-512, 2004.

[7] P. G. Malchev, C. T. David, S. J. Picken, and A. D. Gotsis, "Mechanical properties of short fibre reinforced thermoplastic blends," Polymer, vol. 46, no. 11, pp. 3895-3905, 2005.

[8] Y. Remond, "Constitutive modeling of viscoelastic unloading of short glass fibre-reinforced polyethylene," Composites Science and Technology, vol. 65, no. 3-4, pp. 421-428, 2005.

[9] F. Farhad, M. Jalil, R. N. Mohamad, and E. Morteza, "Dynamic rheological and mechanical behaviours of poly(dimethylsiloxane) /low density polyethylene immiscible blends: Interfacial modification via reactive blending," Iranian Polymer Journal, vol. 17, pp. 755-765, 2008.

[10] C. Nakason and S. Saiwari, "Effect of grafted maleic anhydride content and recyclability of dynamically cured maleated natural rubber/polypropylene blends," Journal of Applied Polymer Science, vol. 110, no. 6, pp. 4071-4078, 2008.

[11] N. Sombatsompop, "Effects of glass fibre content and coolant temperature on temperature and crystallinity profiles of PP melt during cooling " Journal of Applied Polymer Science, vol. 82, no. 9, pp. 2087-2097, 2001

[12] K. Kanna and A. Misra, "Short glass fibre reinforced PA6 and ABS blends: Mechanical properties and morphology," International Polymer Processing, vol. 9, no. 2, pp. 184-192, 1994.

[13] S. Y. Fu, B. Lauke, E. Mäder, C.Y.Yue, and X. Hu, "Tensile properties of short-glass-fiber-and short-carbon-fiber-reinforced polypropylene composites," Composites Part A : Applied Science and Manufactureing, vol. 31, no. 10, pp. 1117-1125, 2000.

[14] K. K. Chawla, "On the applicability of the "Rule-of-Mixtures" to the strength properties of metal-matrix composites," Revista Brasileira de Fisileira, vol. 4, no. 3, pp. 411-418, 1974.

[15] M. Jamal, T. Mehdi, G. Ismaeil, and C. H. John, "Prediction of the elastic modulus of wood/flour/kenaf fibre/polypropylene hybrid composites," Iranian Polymer Journal, vol. 16, no. 4, pp. 271-278, 2007.

[16] D. Basu, A. N. Banerjee, and A. Misra, "Comparative rheological studies on jute-fiber-and glass-fiber-filled polypropylene composite melts," Journal of Applied Polymer Science, vol. 46, no. 11, pp. 1999-2009, 1992

[17] Y. Nishitani, I. Sekiguchi, B.Hausnerova, Y. Nagatsuka, and T. Kitano, "Influence of addition of styrene-ethylene/butylenes-stytene copolymer on rheological, mechanical, and tribological properties of polyamide manocomposites, "Polymer Composite, vol. 9, no. 3, pp. 1-9, 2001.

[18] B. Hausnerova, N. Zdrazilova, T. Kitano, and P. Saha, "Viscoelastic properties of flexible organic fiber composites," International Polymer Processing, vol. 20, no. 1, pp. 19-26, 2005

[19] J. W. Chung, S. J. Han, and S. Y. Kwak, "Dynamic viscoelastic behavior and molecular mobility of acrylonitrile-butadiene copolymer nanocomposites with various organoclay loadings," Composites Science and Technology, vol. 68, no. 6, pp. 15551561,2008

[20] R. H. German, Powder Injection Moulding, 2nd ed. Princeton, NJ: MPIF, 1995. 